OPEN ACCESS

Edited by:

Ashwani Kumar Mishra, All India Institute of Medical

Sciences, India

Reviewed by:

Enamul Kabir,

University of Southern

Queensland, Australia Shobhit Jain,

Banaras Hindu University, India

${ }^{*}$ Correspondence: Reem Kayyali

r.kayyali@kingston.ac.uk

Specialty section: This article was submitted to

Public Mental Health, a section of the journal

Frontiers in Psychiatry

Received: 18 August 2020 Accepted: 09 February 2021

Published: 19 March 2021

Citation:

Al-Zawaadi A, Hesso I and Kayyali R (2021) Mental Health Among School-Going Adolescents in Greater London: A Cross-Sectional Study. Front. Psychiatry 12:592624. doi: 10.3389/fpsyt.2021.592624

\section{Mental Health Among School-Going Adolescents in Greater London: A Cross-Sectional Study}

\author{
Asmaa Al-Zawaadi, Iman Hesso and Reem Kayyali* \\ School of Life Sciences, Pharmacy and Chemistry, Kingston University London, Kingston upon Thames, United Kingdom
}

Objectives: Mental health problems are among the leading causes of health-related disability among children and adolescents worldwide. However, there is still a global challenge in terms of gathering consistent epidemiological information about the issue. The present study was designed to describe various mental health issues and factors associated with negative feelings among adolescents in Greater London.

Methods: This is a cross sectional study, using a self-administered questionnaire (Cronbach's alpha $=0.742$ ). A convenience sampling strategy was used to recruit participants who were school/college-attending adolescents, aged 11-19. A minimum sample size of 199 was required (95\% confidence interval, 5\% margin of error, and $15.3 \%$ population proportion). The study was conducted between February and April 2016 in Greater London. Descriptive statistics and inferential statistics including chi square, Spearman correlation, and binary logistic regression were used to identify the key findings. Data analysis was performed using SPSS v21.

Results: A total of 526 out of 1,920 surveys were collected across 18 secondary schools and two colleges, giving a response rate of $27.4 \%$. More than half of the adolescents reported to be either neutral $(41.4 \%)$, sad $(7.8 \%)$, or very sad $(2.8 \%)$, whereas $48 \%$ reported to be either happy (35\%) or very happy (13\%). Difficulties in relationships and hectic schedules were among the most stressful situations affecting adolescents' mental health. Discrimination was identified as the main predicting factor with five-fold increase in odds of having negative mental health symptomatology. Other significant risk factors identified were age, gender, smoking, and health comorbidities.

Conclusion: Discrimination was identified as the most predictive factor influencing negative symptomatology among the study cohort. The study had several limitations, most notably the use of a non-validated surrogate measure for mental health, in addition to the exclusion of adolescents aged 10-11 years, school/college dropouts and non-school-going adolescents. A similar study on a national scale is highly recommended to determine the real magnitude of the problem, which would be the starting point toward proper tackling of mental health issues and associated complexities among the adolescent population across England.

Keywords: mental health, adolescents', risk factors, causes, bullying, discrimination 


\section{INTRODUCTION}

Mental health problems are among the leading causes of healthrelated disability among children and adolescents worldwide (1). The prevalence of mental health disorders has been reported to increase in adolescence. Worldwide, estimates indicate that up to $20 \%$ of children and adolescents have mental health disorders, which accounts for a large portion of the global burden of the disease $(1,2)$. In Europe, mental health disorders have an estimated prevalence of $8-23 \%$ of the child and adolescent population (3). Adolescence is a key period in life for establishing the foundation for health and well-being in adulthood (4). Existing evidence in the literature suggests that a substantial proportion of mental health problems in adults originate in mid-to-late adolescence and contribute to the existing burden of the disease among young people and in later life $(1,5)$; three quarters of mental health problems start before the early 20 s $(4,6)$.

There are 7.4 million young people aged 10-19, representing $11 \%$ of the total population of the United Kingdom (UK) in 2017, with $21.5 \%$ estimated to be from an ethnic minority (6). According to 2017 estimates, young people aged 10-19 live in 4.8 million households, mainly with married parents $(62 \%)$, lone parents $(23 \%)$, or cohabitating parents $(9 \%)$, and 1.9 million are living in the most deprived areas (6). In the UK, the British Child and Adolescent Mental Health Surveys in 1999 and 2004 reported that 1 in 10 children and young people under the age of 16 had a diagnosed mental disorder. Among the 11-16-year-old age group, $13 \%$ of boys and $10 \%$ of girls had a mental health issue; most commonly conduct disorders, hyperkinetic, emotional disorder, and autism spectrum disorder (ASD) $(4,7)$. The most common problems for boys are conduct disorders, whereas the most common problems for girls are emotional disorders (4). The more recent estimates in England showed that one in seven adolescents (15.3\%) aged 1119 met the criteria for having a mental health disorder at the time of the 2017 Mental Health of Children and Young People Survey $(8,9)$. A very recent follow-up survey was conducted in July 2020 during the coronavirus-2019 (COVID-19) pandemic which showed that $17.6 \%$ of adolescents (one in six) aged 1116 years were identified with a probable mental health disorder, an increase from $12.6 \%$ of adolescents (one in eight) in 2017 (9). According to the more recent statistics, emotional disorders such as anxiety and depression were found to be the most common mental disorders experienced by young people $(8,9)$. The economic burden associated with mental health disorders during childhood and adolescence is substantially high. In Europe, the economic consequences of child and adolescent mental health disorders are significant in terms of health services, social services, education system, criminal justice system, voluntary services, and productivity costs. The mean overall societal costs were estimated to range from $€ 7,376$ to $€ 64,703$ per child/adolescent in Europe annually (3). In the UK, mental health disorders were estimated to result in increased costs of between $£ 11,030$ and $£ 59,130$ annually per child including direct costs to families and costs related to education, social services, and youth justice (7).
Several factors have been identified to influence mental health among adolescents, including bullying (10-12), discrimination (13-18), low socioeconomic status $(19,20)$, low physical activity, high screen time (ST) (12, 21-27), smoking, and alcohol drinking (28-30). Poor family functioning has also been reported in the literature to have a robust link to poor adolescent mental health (31).

Mental health problems have important implications on various aspects of adolescents' lives including their ability to engage with education, engage in constructive family relationships, and make and keep friends in addition to developing self-dependence. Hence, detection, treatment, and support are all fundamental parts of the services to be provided to this young population (4). Despite the increased recognition of the prevailing burden and negative impact of mental health disorders among children and adolescents (3, 5), a global challenge still exists in terms of the capacity to gather consistent epidemiological information about the issue. The latter is important in order to provide a context for understanding the magnitude of this clinical problem, which in return would allow the identification of gaps in the services to support child/adolescent mental health, the quantification of child and adolescent mental disorders, the economic costs of impairment, or the lost potential for the individual or society (2). Therefore, this study aimed to describe the various mental health issues and factors contributing to them among adolescents in Greater London.

\section{METHODS}

\section{Research Design}

This is a quantitative cross-sectional survey study among adolescents in schools and colleges. The study was conducted across four boroughs in London: Kingston upon Thames, Richmond upon Thanes, Croydon, and Wandsworth.

\section{Participants and Recruitment}

A convenience sampling strategy was used when approaching schools/colleges to recruit participants. The total number of adolescents aged 11-19 years in the four boroughs was 104,000 . The maximum prevalence of mental health disorders as determined by the 2017 statistics for young people aged 1119 in England is $15.3 \%$ (8). The target sample size needed to achieve the study objectives with a sufficient statistical power of $80 \%$ was calculated using the Raosoft sample size calculator. Hence, the required sample size was 199 participants using a margin of error of $5 \%$, a confidence interval of $95 \%$, and a $15.3 \%$ population proportion.

Data collection took place between February and April 2016. A letter was designed for head teachers and students' well-being counselor to introduce the project, explain the purpose of the survey, and get the schools' permission to participate in the study.

Surveys were either sent to the school and then collected once completed or conducted directly by one of the research teams inside the school/college. Participants were informed about the study via an information sheet, which was attached 
with every single questionnaire. The information sheet provided details about the research aims, the questionnaire content, confidentiality, choice of participation, and withdrawal, as well as the contact details of the research team. Completion of the questionnaire indicated implied consent on the part of the student. Only fully completed questionnaires were included in the final analysis.

\section{Data Collection Tool}

Data collection was performed using a paper-based questionnaire, consisting of 31 questions in total, covering four sections. The questionnaire was developed by the authors to address the study aims. The questionnaire consisted mostly of closed-ended questions including tick-box, pictorial, multipleresponse, and contingency questions. The themes of the tool were adopted from the Renfrewshire community health partnership "Health and well-being survey of young people in Renfrewshire 2013" which aimed at establishing baseline information on the health and well-being of pupils aged 13-18 years across secondary schools in Renfrewshire (32). The first section consisted of seven questions (questions 1-7) covering demographics. The second section included seven questions (questions 8-14) investigating the participants' lifestyle. The third section comprised 11 questions (questions 15-25), which aimed at evaluating adolescents' mental health. In this section, adolescents were asked to rate their general feelings via a pictorial question with emoji facial expressions (question no. 15) on a scale from 1 to 5 with one indicating very happy to five indicating very sad. In addition, the third section included five multiple-response questions (questions 19, 22, 23, 24, and 25) comprising 15 statements signifying negative mental health feelings/symptomatology associated with common mental health disorders which are anxiety and depression, in order to identify the frequency of these feelings among adolescents in the last 6 months. The questions $(19,22,23,24$, and 25) captured core symptomatologies/feelings associated with the two common mental health disorders: anxiety and depression. Across the questions, some symptomatologies were asked more than once; hence, the symptomatologies captured within these questions and the weighting of each feeling/symptomatology were as follows: sadness (weight 2-mentioned twice), feeling nervous, anxious or on edge (weight 2), feeling restless (weight 1), pervasive low mood (weight 2), loss of pleasure in activities (weight 1), feeling guilty or worthless (weight 1), marked change in appetite, weight or sleep (weight 3), tiredness and poor concentration (weight 2), and thoughts of dying or suicide (weight 1 ).

The rest of the questions in section three explored participants' experiences about aspects such as challenging situations in addition to discrimination and bullying. The last section included six questions (questions 26-31) focusing on adolescents' usage of social media and ST. The questionnaire took an average of 5-8 min to complete.

The questionnaire items were evaluated for internal reliability using Cronbach's $\alpha$. Cronbach's alpha coefficient was 0.742 , which is within the recommended range of $0.7-0.9(33,34)$.
TABLE 1 | Questions addressing negative symptomatology in the study questionnaire.

\begin{tabular}{ll}
\hline Question & Negative symptomatology feeling phrases \\
\hline Q15 & 1. General feeling (Neutral/Sad/Nery sad) \\
Q19 & 2. I was frequently feeling up and down \\
3. I lost or gained weight without trying to, or my appetite have & changed \\
& 4. I felt frequently sad, like I couldn't go to school \\
5. I felt slowed down compared to my usual pace & 6. I stopped having fun doing things that I used to enjoy \\
7. Panic attacks (Yes) & 8. Low in mood (Yes) \\
923 & my life \\
1024 I felt that my worry was out of control & 11. I felt restless, agitated and tense \\
12. I had troubles sleeping & 13. I could not fall or stay asleep \\
14. I felt exhausted \\
15. I felt worthless or guilty \\
16. I keep thinking about death
\end{tabular}

Each response indicates a score of one. A maximum score of 16 can be obtained based on the summation of responses from all the questions.

\section{Pilot Study}

After attaining ethical approval, a pilot study was conducted among five adolescents in a college in Kingston for assessing the face and content validity of the questionnaire. The outcome of the pilot indicated the need for some minor amendments of some questions. To avoid any type of bias, the questionnaires filled in the pilot study were excluded from the final analysis.

\section{Data Analysis}

All responses were coded and entered into SPSS for statistical analysis. Descriptive statistics were carried out to describe participants' characteristics and data regarding the basic features of the study. Proportions/percentages were used to describe categorical variables. Comparisons of proportions between groups were performed using Chi-square tests. Adolescents' feeling scorings were calculated based on the sum of responses obtained from the symptomatology questions (questions 15, 19, $22,23,24$, and 25) included in section three. Each response reflecting a negative symptomatology feeling indicated a score of one with a maximum score of 16 that can be obtained via the summation of the responses for the five questions (Table $\mathbf{1}$ ).

The correlation between general feeling status among participants and feeling scorings was determined using Spearman's rank correlation coefficient, with data about feeling scorings being categorized/dichotomized based on a cutoff point of $50 \%$ to establish dominance of negative feelings and identify causing factors. Hence, a feeling score of $\geq 50 \%$ indicates dominance of negative mental health, whereas a score of $<50 \%$ indicates less dominance of negative mental health. Furthermore, 
ST was classified based on the recommended 2-h limit per day for adolescents $(24,25)$.

Furthermore, a multiple binary logistic regression was conducted to determine risk factors influencing mental health based on categorization of feeling scorings, with results being expressed as odds ratios (ORs) with $95 \%$ confidence limits. The set of possible predictors considered was age, gender, ethnicity, birth, weekly income, physical activity, ST, presence of health conditions, smoking, drinking, living with parents, bullying, and discrimination. $P$-values below 0.05 indicated statistical significance for all analyses.

\section{Ethical Approval}

Ethical approval to conduct this study was granted from the Delegated Research Ethics Committee at the academic institution of the corresponding author (Ref: 1213/045).

\section{RESULTS}

\section{Response Rate, Demographics, and Lifestyle}

Forty-four primary and secondary schools and colleges were approached. Twenty secondary schools and colleges agreed to participate, whereas all primary schools in the study areas denied participation given the sensitivity of the topic. Therefore, the age range of participants was 11-19, given that the starting age of students at secondary schools in England is 11 years. In total, 1920 surveys were distributed across the schools and colleges and 526 surveys were collected, giving a response rate of $27.4 \%$. Participants' demographics are summarized in Table 2 . Interestingly, only $8 \%(n=$ 41/526) of the surveyed adolescents follow the recommendations indicated by the National Institute for Health and Care Excellence (NICE) guidelines for children and young people which is playing sports 7 days a week (35). On the other hand, $17 \%$ of the adolescents reported to be currently smoking and nearly half (49\%) reported to have health problems (Table 2).

Participants were asked about the amount of time they spend on laptop/phone per day. Nearly two third of the study cohort $(68.1 \%, n=358 / 526)$ reported to have a ST $\geq 2$ h/days.

\section{General Feelings Status and Feeling Scorings}

Students were asked to rate their general feelings via a pictorial question with emoji facial expressions. The majority of respondents indicated feeling neutral $(41.4 \%, n=218 / 526)$, followed by $35 \%$ ( $n=184 / 526)$ feeling happy, $13 \%(n=68 / 526)$ feeling very happy, with least percentages for being sad $(7.8 \%, n$ $=41 / 526)$, or very sad $(2.8 \%, n=15 / 526)$. The participants were clustered based on feeling scorings, with scores of $\geq 50 \%$ (i.e., score $\geq 8 / 16$ ) indicating dominance of negative symptomatology. Three quarters of the participants $(74 \%, n=387 / 526)$ had a feeling scoring of $<50 \%$ indicating less dominance of negative symptomatology, whereas a quarter $(26 \%, n=139 / 526)$ had a feeling scoring of $\geq 50 \%$ indicating a negative mental feeling. A
TABLE 2 | Demographics of study participants.

\begin{tabular}{|c|c|c|}
\hline Characteristics & Number & Percentage \\
\hline \multicolumn{3}{|l|}{ Gender } \\
\hline Male & 251 & 48 \\
\hline Female & 275 & 52 \\
\hline \multicolumn{3}{|l|}{ Age } \\
\hline $11-15$ years & 172 & 33 \\
\hline 16-19 years & 354 & 67 \\
\hline \multicolumn{3}{|l|}{ Birthplace } \\
\hline UK & 376 & 71.5 \\
\hline Outside UK & 150 & 28.5 \\
\hline \multicolumn{3}{|l|}{ Ethnicity } \\
\hline White & 257 & 49 \\
\hline Indian & 15 & 3 \\
\hline Pakistani & 29 & 5.5 \\
\hline Bangladeshi & 8 & 1.5 \\
\hline African Black & 62 & 12 \\
\hline Caribbean Black & 53 & 10 \\
\hline Other black & 13 & 2.5 \\
\hline Chinese & 7 & 1 \\
\hline Other Asian & 50 & 9.5 \\
\hline Persian & 10 & 2 \\
\hline Arab & 22 & 4 \\
\hline \multicolumn{3}{|l|}{ Smoking } \\
\hline Yes & 89 & 17 \\
\hline No & 437 & 83 \\
\hline \multicolumn{3}{|l|}{ Drinking } \\
\hline Yes & 222 & 42 \\
\hline No & 304 & 58 \\
\hline \multicolumn{3}{|l|}{ Health problem } \\
\hline Yes & 257 & 49 \\
\hline No & 269 & 51 \\
\hline \multicolumn{3}{|c|}{ Type of health problem } \\
\hline Physical disability & 102 & 19 \\
\hline Diabetes & 3 & 1 \\
\hline ADHD & 16 & 3 \\
\hline Dyslexia & 76 & 14 \\
\hline Eczema & 54 & 10 \\
\hline Epilepsy & 4 & 1 \\
\hline Autism/ASD & 9 & 2 \\
\hline Painful joints & 51 & 10 \\
\hline Learning difficulties & 69 & 13 \\
\hline Other & 257 & 49 \\
\hline None & 269 & 51 \\
\hline \multicolumn{3}{|c|}{ Physical activity (days/week) } \\
\hline$<7$ days a week & 485 & 92 \\
\hline 7 days a week & 41 & 8 \\
\hline \multicolumn{3}{|l|}{ Weekly income } \\
\hline Yes & 293 & 56 \\
\hline No & 233 & 44 \\
\hline
\end{tabular}

Total $N=526$.

significant positive association was found between general feeling status in terms of expressing sad feelings and feeling scoring of $\geq 50 \%$ ( $r s=0.374, p<0.0001)$. 
Further analysis was conducted among adolescents scoring $\geq 50 \% \quad(n=139)$ to identify the frequency of negative symptomatology phrases. The vast majority $(97.8 \%, n=136 / 139)$ reported being in low mood in the past 6 months. This was followed by feeling anxious, worried, or scared about a lot of things in life $(85.6 \%, n=119 / 139)$, frequently feeling up and down $(74.8 \%, n=104 / 139)$, and having panic attacks in the last 6 months $(74.1 \%, n=103 / 139)$. Equal responses were obtained for feeling exhausted and feeling worthless or guilty $(71.2 \%, n=$ 99/139). Interestingly, more than two-thirds $(67.6 \%, n=94 / 139)$ reported to have trouble in sleeping and more than half $(53.2 \%, n$ $=74 / 139$ ) reported difficulties in falling or staying asleep. Feeling restless, agitated, and tense was reported by $59.7 \%(n=83 / 139)$, and more than half $(53.2 \%, n=74 / 139)$ mentioned to stop having fun and doing enjoyable things. Another important negative symptomatology reported by nearly half of the adolescents
(48.2\%, $n=67 / 139)$ was related to the constant thinking about death (Figure 1).

\section{Main Causes of Mental Health Problems}

Participants were asked about the most challenging and stressful situations that could negatively affect their mental health using a multiple-choice question, which provided 962 responses in total. Relationship difficulties was the main struggle for the young population with $20.5 \%(n=197 / 962)$ responses, followed by hectic schedules $(15.9 \%, n=153 / 962)$. Sudden change, discrimination, and financial hardships were reported by $14.6 \%$ $(n=140 / 962), 12.4 \%(n=119 / 962)$, and $11.9 \%(n=114 / 692)$, respectively. Feelings of isolation and serious challenges were equally identified as causes of stress with $10.3 \%(n=99 / 962)$ and $10.2 \%(n=98 / 962)$ of responses, respectively. Unsafe neighborhood was the least reported with $4.4 \%(n=42 / 962)$.

\section{Negative symptomatology phrase among adolsecents scoring $\geq \mathbf{5 0} \%$}

I felt that my worrying was out of control

I felt frequently sad, like I couldn't go to school

I lost or gained weight without trying to, or my appetite have changed

I felt slowed down compared to my usual pace

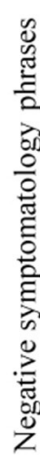

के

I keep thinking about death

I could not fall or stay asleep

I stopped having fun and doing things that I used to enjoy

I felt restless, agitated and tense

I had troubles sleeping

I felt worthless or guilty

I felt exhausted

Panic attack

I was frequently feeling up and down

I was feeling anxious, worried, or scared about a lot of things in my life

Low mood

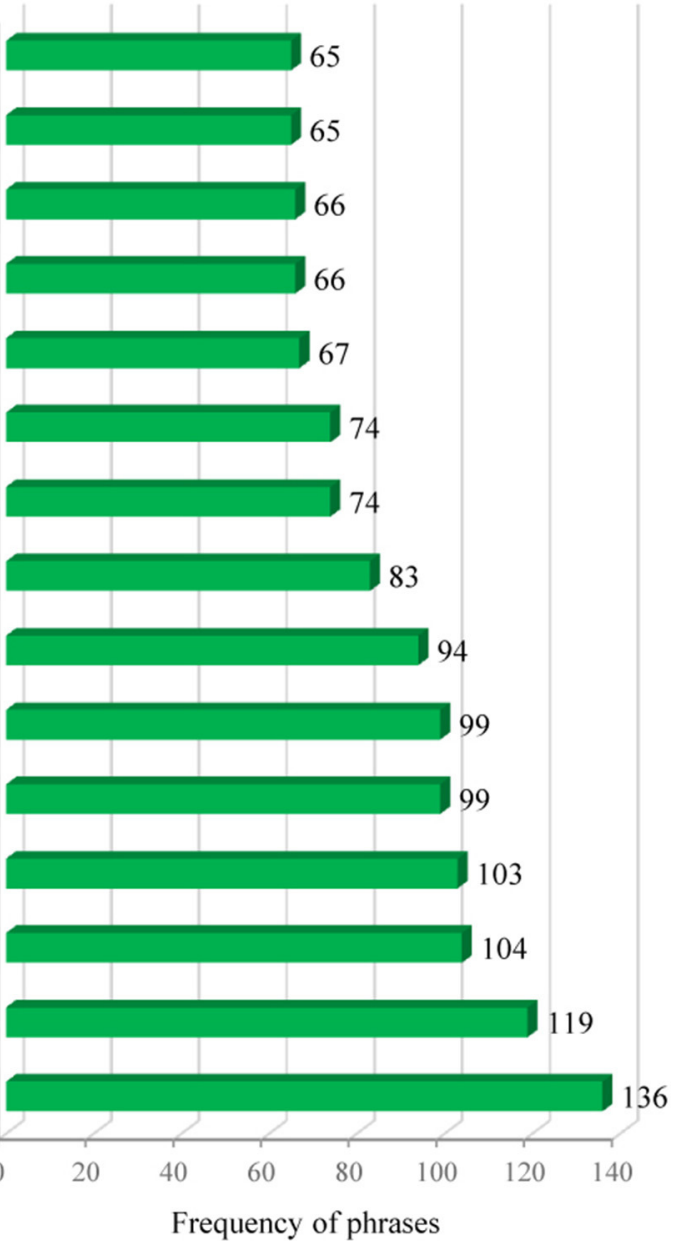

FIGURE 1 | Frequency of negative symptomatology phrases among adolescents with feeling scorings $\geq 50 \%$. 
Experiences and causes of discrimination and bullying were further elicited from the participants via multiple-response questions. A total of $60 \%(n=316 / 526)$ of the adolescents reported to have experienced discrimination in the past 6 months. Body size, appearance, ethnicity, and skin color were the most reported causes of discrimination, with $18.8 \%$ ( $n=$ $157 / 833), 13 \%(n=108 / 833), 12 \%(n=100 / 833)$, and $11 \%$ ( $n=92 / 833)$ of responses, respectively. This was followed by accent (9.6\%, $n=80 / 833)$, gender (9.5\%, $n=79 / 833)$, nationality $(7.9 \%, n=66 / 833)$, age $(7.3 \%, n=61 / 833)$, and language $(5.3 \%, n=44 / 833)$. Discrimination based on sexual orientation and disability were the least reported with $2.6 \%(n=22 / 833)$ and $2.2 \%(n=18 / 833)$ of responses, respectively. As for bullying, the majority of participants $(78.3 \%$, $n=412 / 526$ ) did not report any form of bullying in the past 6 months. Among those who were bullied $(21.7 \%, n=$ $114 / 526)$, this occurred mostly at school $(65.8 \%, n=75 / 114)$, followed by other places $(22.8 \%, n=26 / 114)$, thereafter at home $(11.4 \%, n=13 / 114)$.

\section{Factors Influencing Mental Health Chi-Square Test of Association of} Sociodemographic, Discrimination, and Bullying With Dominance of Negative Mental Feelings

The chi-square test revealed significant associations between dominance of negative mental feelings and each of age, gender, smoking, drinking, bullying, physical activity, discrimination, health conditions, and family instability (not living with both parents) (Table 3). Around a third of the female adolescents (33.5\%) and those who drink $(36.5 \%)$ reported dominance of negative mental feelings. While only $10.5 \%$ of young people aged below 16 reported feelings scoring $\geq 50 \%$, Table 3 shows that this percentage was more than triple (34\%) in those aged above 16. Additionally, $22 \%$ of non-smoking adolescents had feelings scoring $\geq 50 \%$; however, the percentage was more than double $(48.3 \%)$ in those who were smoking. Interestingly, dominance of negative mental health was reported by $39.2 \%$ of adolescents who experienced discrimination vs. only $7.1 \%$ who did not report any form of discrimination. As for bullying, $22 \%$ of adolescents

TABLE 3 | Association of sociodemographic factors, bullying, and discrimination with mental health (dominance of negative mental feelings).

\begin{tabular}{|c|c|c|c|c|}
\hline \multicolumn{2}{|c|}{ Participants' characteristics } & \multirow{2}{*}{$\begin{array}{c}\text { Feeling scoring } \geq \mathbf{5 0} \%, \boldsymbol{n}(\mathbf{\%}) \\
47(18.3 \%)\end{array}$} & \multirow{2}{*}{$\begin{array}{l}\text { Chi square }\left(\boldsymbol{X}^{2}\right) \\
\boldsymbol{X}^{2}(1)=14.64\end{array}$} & \multirow{2}{*}{$\begin{array}{l}\boldsymbol{P} \text {-value } \\
<0.0001\end{array}$} \\
\hline Gender & Male & & & \\
\hline & Female & 92 (33.5\%) & & \\
\hline \multirow[t]{2}{*}{ Age } & $<16$ & $18(10.5 \%)$ & $x^{2}(1)=33.48$ & $<0.0001$ \\
\hline & $\geq 16$ & $121(34 \%)$ & & \\
\hline Birth place & In the UK & 100 (26.6\%) & $X^{2}(1)=0.02$ & 0.889 \\
\hline Smoking & No & 96 (22\%) & & \\
\hline \multirow[t]{2}{*}{ Drinking } & Yes & $81(36.5 \%)$ & $\boldsymbol{X}^{\mathbf{2}}(1)=19.99$ & $<0.0001$ \\
\hline & No & $58(19.1 \%)$ & & \\
\hline Weekly income & Yes & 77 (26.3\%) & $\boldsymbol{X}^{2}(1)=0.007$ & 0.932 \\
\hline Ethnicity & Non-white & $68(26.7 \%)$ & & \\
\hline \multirow[t]{2}{*}{ Physical activity } & Below recommended guidelines & $134(27.6 \%)$ & $X^{2}(1)=4.63$ & 0.031 \\
\hline & Above recommended guidelines & $5(12.2 \%)$ & & \\
\hline \multirow[t]{2}{*}{ Health conditions } & Yes & 89 (34.6\%) & $X^{2}(1)=17.39$ & $<0.0001$ \\
\hline & No & 50 (18.6\%) & & \\
\hline \multirow[t]{2}{*}{ Living with } & Both parents & $80(23.4 \%)$ & $\boldsymbol{X}^{2}(1)=4.62$ & 0.031 \\
\hline & Others & $59(32.1 \%)$ & & \\
\hline \multirow[t]{2}{*}{ Bullying } & Yes & $46(40.4 \%)$ & $X^{2}(1)=14.51$ & $<0.0001$ \\
\hline & No & 93 (22.6\%) & & \\
\hline Discrimination & Yes & 124 (39.2\%) & $X^{2}(1)=66.85$ & $<0.0001$ \\
\hline
\end{tabular}


TABLE 4 | Binary logistic analysis for risk factors affecting mental health in adolescents.

\begin{tabular}{|c|c|c|c|}
\hline \multirow[b]{2}{*}{ Characteristics } & \multicolumn{3}{|c|}{$\begin{array}{c}\text { Dominance of negative mental health } \\
\text { feelings/symptomatology associated with } \\
\text { common mental health disorder which are } \\
\text { anxiety and depression (feeling scoring } \\
\geq 50 \% \text { ) }\end{array}$} \\
\hline & OR & $95 \% \mathrm{Cl}$ & $P$-value \\
\hline Gender (female) & 1.85 & $1.16-2.94$ & 0.01 \\
\hline Age ( $\geq 16$ years) & 2.46 & $1.23-4.92$ & 0.01 \\
\hline Birthplace place in the UK & 1.09 & $0.64-1.83$ & 0.746 \\
\hline Smoking & 1.82 & $1.04-3.21$ & 0.036 \\
\hline Drinking & 1.07 & $0.64-1.8$ & 0.780 \\
\hline Presence of weekly income & 0.73 & $0.45-1.17$ & 0.196 \\
\hline $\begin{array}{l}\text { Physical activity (below } \\
\text { recommended guidelines) }\end{array}$ & 1.57 & $0.54-4.56$ & 0.407 \\
\hline Ethnicity (black) & 0.68 & $0.35-1.31$ & 0.253 \\
\hline Ethnicity (white) & 1.19 & $0.68-2.05$ & 0.533 \\
\hline $\begin{array}{l}\text { Presence of health } \\
\text { conditions }\end{array}$ & 1.66 & $1.04-2.65$ & 0.033 \\
\hline Living with both parents & 0.90 & $0.57-1.44$ & 0.685 \\
\hline Bullying & 1.44 & $0.86-2.39$ & 0.157 \\
\hline Discrimination & 5.18 & $2.80-9.52$ & $<0.0001$ \\
\hline Screen time $>2 \mathrm{~h}$ & 1.34 & $0.77-2.31$ & 0.293 \\
\hline
\end{tabular}

who did not experience bullying in the last 6 months reported dominance of negative mental feelings, vs. $40.4 \%$ of those who did (Table 3). Nearly a third (32.1\%) of adolescents not living with both parents had feelings scoring $\geq 50 \%$, vs. $23.4 \%$ of those living with their parents.

Ethnicity, birthplace, and income were not associated with dominance of negative mental feelings.

\section{Multivariate Association of Sociodemographic, Discrimination, and Bullying With Dominance of Negative Mental Feelings}

Certain factors were found to influence mental health in the study population, as indicated by the dominance of negative feeling (feeling scoring $\geq 50 \%$ ). Gender was found to be a significant influencing factor, with female participants having $\sim 2$ odds more than males at scoring $\geq 50 \%(p=0.01)$. Participants aged $\geq 16$ were found to be 2.46 times more likely to have feeling scoring $\geq 50 \%$, indicating age to be another significant factor $(p=0.01)$ (Table 4).

Remarkably, participants who experienced discrimination in the last 6 months were 5.18 times more likely to have feeling scoring $\geq 50 \%(p<0.0001)$. The odds of having feeling scoring $\geq 50 \%$ was 1.82 times higher in adolescents who were smoking $(p=0.036)$. Adolescents suffering from a health condition had an odds ratio of 1.66 for scoring $\geq 50 \%$ ( $p=0.033$ ). High ST ( $\geq 2$ h/days), bullying, and doing less physical activity were found to increase the likelihood of scoring $\geq 50 \%$ by $1.34,1.44$, and 1.57 times, respectively, yet the effect of these factors was not significant (Table 4). Additionally, factors such as ethnicity, birthplace, income, and drinking were not found to have any significant effect on adolescents having negative mental health symptomatology (Table 4).

\section{Use of Social Media and Sources of Support Among Adolescents}

In general, the most commonly used social media sites among adolescents were YouTube with $22.4 \%$ of responses $(n=$ $357 / 1,592)$, followed by Instagram (20.2\%, $n=322 / 1,592)$, WhatsApp $(17.5 \%, n=279 / 1,592)$, and Snapchat $(16.8 \%, n$ $=268 / 1,592)$. Facebook and Twitter were the least used social media sites.

Identification of main sources of support was acquired from participants by means of a multiple-response question, which yielded a total of 991 responses. Friends were identified to be the main source of support among the surveyed adolescents with $33.8 \%$ of responses $(n=335 / 991)$ followed by parents $(31.5 \%$, $n=312 / 991)$. The third main form of support was the internet (10.4\%, $n=103 / 991)$, followed by schoolteachers $(7 \%, n=$ 69/991). The option "No one" attained 53 responses, constituting $5.3 \%$ of responses (Figure 2).

Social media was not reported as a main source of support (Figure 2). However, when adolescents were specifically asked about the use of social media in relation to mental health, one-third ( $34 \%, n=179 / 526)$ reported to share mental health problems on social media sites, vs. two-third ( $66 \%, n=347 / 526)$ who did not. Participants were also asked to indicate which social media sites they would prefer to use for seeking mental health support, $42 \%$ of the responses $(n=295 / 704)$ indicated none. YouTube was the most preferred site for seeking support with $19.7 \%$ of responses $(n=139 / 704)$ and WhatsApp thereafter with $12.5 \%$ of responses. Equal responses were provided for Facebook (6.8\%) and Snapchat (6.7\%). Instagram and Twitter were the least reported social media sites in this regard (Figure 3). The reasons behind using social media for support were further elicited by a contingency question. Interestingly, being less embarrassing was reported to be the main reason for using social media with $23.2 \%$ of responses $(n=102 / 439)$, followed by the ability to seek advice from people with similar problems $(20.5 \%, n=90 / 439)$, the ability to gain a wide range of opinions $(17.3 \%, n=76 / 439)$, and saving time $(14.4 \%, n=63 / 439)$. Participants also reported to seek social media support because they feel they will not be understood as highlighted in $13.9 \%$ of the responses $(n=$ 61/439). Interestingly, privacy concerns was the least reported reason with $10.7 \%$ of responses $(n=47 / 439)$.

\section{DISCUSSION}

Using emoji facial expressions, more than half of the participating adolescents reported to be either neutral, sad, or very sad. In the current study, the bivariate analysis showed multiple factors to be associated with negative mental health, which is reflective of the literature. These include age, gender, smoking, drinking, discrimination, bullying, presence of health conditions, low physical activity, and high ST. 


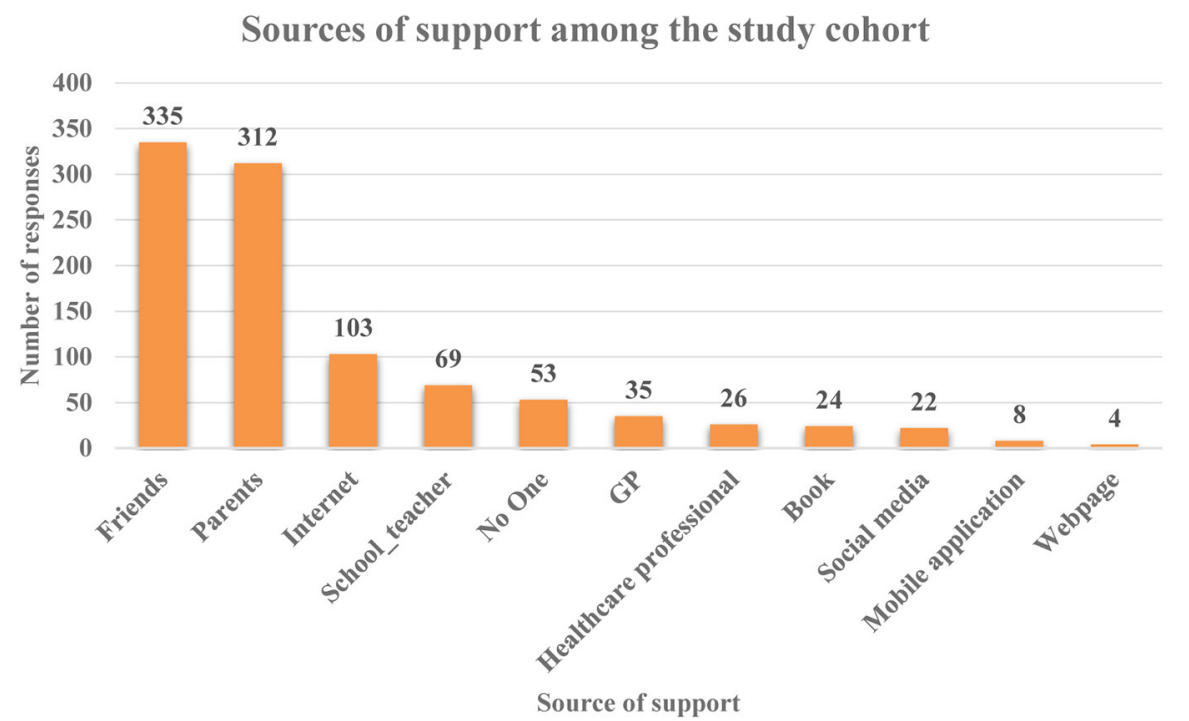

FIGURE 2 | Sources of support among the study cohort. Number of responses, $n=991$.

\section{Use of social media sites for mental health support}

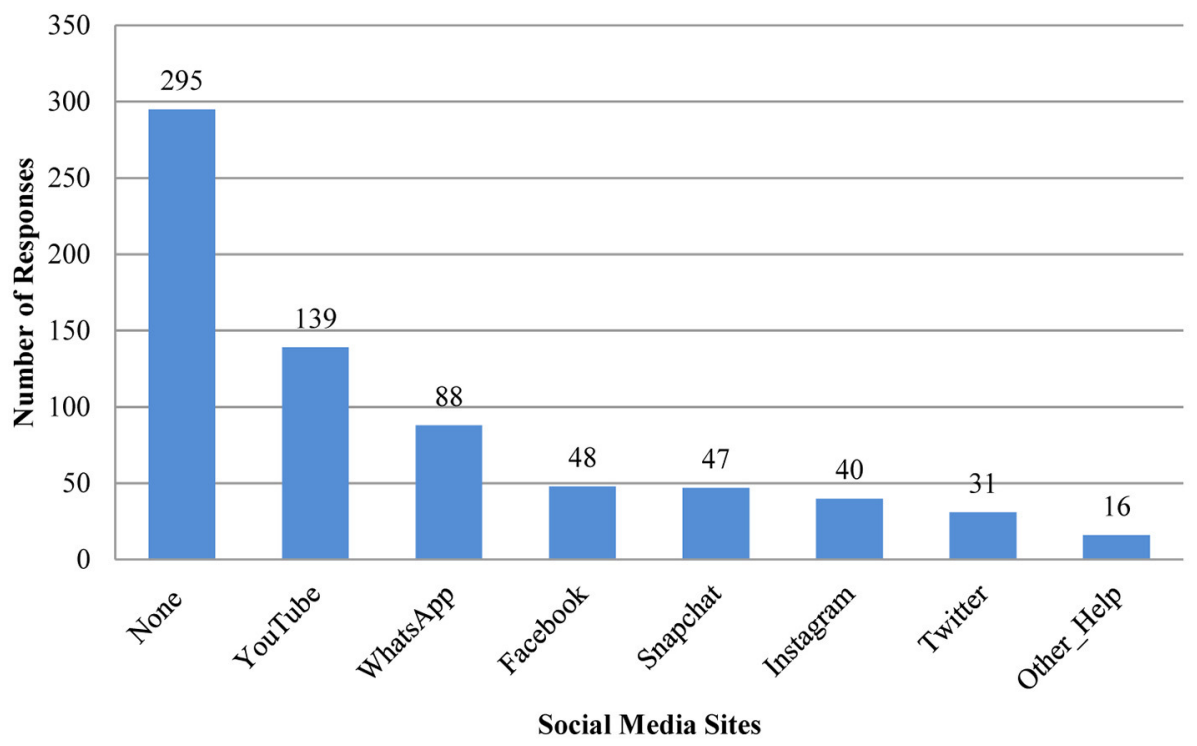

FIGURE 3 | Use of social media sites among the study cohort for mental health support. Number of responses, $n=704$.

However, upon conducting multivariate analysis, it became clear that discrimination was the most predictive factor for negative mental health, with a fivefold increase in odds of having negative mental health feelings (a score of $>50 \%$ ) among the participating adolescents. A plausible explanation of the current finding is related to the absence of well-established schemes for tackling discrimination at schools/colleges at the time of conducting the study. The detrimental effect of discrimination on both mental and physical health has been identified by several scholars in the literature whether among adults or adolescent $(13-18,36)$. Discrimination was experienced by $60 \%$ of the study sample, and 833 responses were provided regarding the causing factors, suggesting that the surveyed adolescents suffered from multiple forms of discrimination. This is more worrying given the results of a previous research which highlighted that experiencing multiple forms of discrimination is associated with worse mental and physical health above the effect of only one form (16). 
Increased age was another risk factor affecting adolescents' mental health in the current study, similar to existing research. Unsurprisingly, a previous research by Kessler et al. (37) suggested that $50 \%$ of mental health conditions are established when individuals reach the age of fourteen. This percentage increases to $75 \%$ by the time the individuals become 24 years of age. Interestingly, another research reported increased odds of feeling depressed/stressed for each year of age among high school-aged adolescents (38). Given that, this suggests that the current study cohort is at high risk of developing further mental health disorders in the next few years. Additionally, this stresses the importance of early detection and tackling of mental health symptoms among adolescents. Female gender was also found to play a significant role in mental health status. This can be due to the fact that females go through mood and behavior fluctuation which occur in conjunction with the phases of menstrual cycle (39). In the current research, females were two times more likely to have negative mental feelings, which is consistent with previous findings in the literature $(12,38)$. In England, a previous research identified gender to be a significant predictor of depressive symptoms among students aged 11-14 years (12), with girls being twice as likely to show depressive symptoms as boys (12). Another study also showed that female gender had $>3$-fold-increased odds of reporting depression and stress (38).

Smoking was another risk factor identified to be significantly influencing mental health. In fact, there has been substantial evidence in the literature linking smoking to mental health disorders in adolescents (28-30). However, other scholars argue for this association to be more complex and bidirectional in nature $(40,41)$. There are many reasons for adolescents to engage in health-compromising behaviors such as smoking; these include childhood abuse, stressful life events, and depressive symptoms (42). Adolescent mental health can be a risk factor for adolescent smoking onset (41), given that adolescents can refer to smoking as a mean of self-medication to cope with psychological distress and depression $(43,44)$, thus building these social habits as an escape mechanism. Some studies have also demonstrated that alcohol and tobacco use during the last phase of adolescence can increase the risk of depression in adulthood (30). Given this context, it can be argued for a vicious cycle of association to be existing between social habits such as smoking and adolescents' mental health. This in return suggests that healthcare professionals should take into consideration the physiological and psychological consequences of smoking and drinking among adolescents when promoting mental well-being among adolescents.

The most commonly sought sources of support in order of frequency were friends, parents, searching the internet, and schoolteachers. Interestingly, family instability was found to be significantly associated with dominance of negative mental health feelings/symptomatologies among the study cohort. This could provide a plausible explanation as to why a third of the participating adolescents chose parents as the second source of support when having mental health problems. The current results also resonate with a previous research in Canada, which emphasized the importance for adolescents to have good relationships with family, friends, and healthcare providers in order to help them achieve control over their mental health condition (45). On the other hand, what was evident from the current study is that the use of social media was not considered as a main source of support. Interestingly, a previous qualitative research highlighted that adolescents perceived social media as a threat to mental well-being in terms of being a cause of mood and anxiety disorders, platform for cyberbullying, and a potential source of addiction (46), which in return could provide a potential explanation to the current results. Given these findings, it can be argued for the need to curb mental health issues on multiple levels including individual, community, and policymakers. As such, identification of sources of support becomes crucial in order to identify the best measures to tackle such a problem. For example, in response to Public Health England (PHE), health link workers are currently introduced into schools in England with the aim of delivering targeted interventions to adolescents including emotional health and wellbeing, smoking, and drug, alcohol, and substance misuse, to list a few. Additionally, link workers are also responsible for delivering training, support, and advice to school staff, young people, and parents about personal, social, and health education (PSHE) and health promotion. Adolescents spend most of their time with teachers, parents, and friends. Hence, schoolteachers, friends, and parents are best placed to recognize and support young people suffering with mental health issues.

\section{Study Limitations}

The use of a non-validated surrogate measure rather than a validated tool to assess mental health issues constituted a major limitation in the current study. In addition, the study had other limitations, including exclusion of adolescents aged 10-11 years, exclusion of school/college dropouts, and non-school going adolescents. The study being observational in nature (non-randomized), using convenience sampling for recruitment, and being conducted in certain boroughs in Greater London, further limits the generalizability of the results on a national scale. Furthermore, studies employing self-administered questionnaires have other potential limitations including recall bias, non-response bias, and social desirability bias (47). Despite these limitations, the current study provides an important insight into the status quo of adolescents' mental health and predicting factors, thus contributing to the existing literature.

However, a study on a national scale with the use of a validated tool is highly recommended as its outcomes may provide an insight into the real magnitude of the problem across the nation.

\section{CONCLUSION}

Several risk factors such as age, gender, social habits (smoking and alcohol consumption), discrimination, bullying, health comorbidities, and sedentary lifestyle were found to be associated with dominance of negative mental health feelings. Among these factors, discrimination was found to be the most predictive factor influencing negative symptomatology among the study cohort. Considering the wide spread of discrimination as unraveled by the current COVID-19 pandemic, a similar study on a national scale with the use of a validated tool is highly recommended 
to determine the real magnitude of the problem and its impact, which would be the gate for the proper tackling of mental health issues and associated complexities among the adolescent population across the nation.

\section{DATA AVAILABILITY STATEMENT}

The raw data supporting the conclusions of this article will be made available by the authors, without undue reservation.

\section{ETHICS STATEMENT}

The studies involving human participants were reviewed and approved by the Science, Engineering and Computing Delegated Ethics Research Committee at Kingston University London (Ref: 1213/045). Written informed consent from the participants' legal guardian/next of kin was not required to participate in this study in accordance with the national legislation and the institutional requirements.

\section{REFERENCES}

1. Kieling C, Baker-Henningham H, Belfer M, Conti G, Ertem I, Omigbodun $\mathrm{O}$, et al. Child and adolescent mental health worldwide: evidence for action. Lancet. (2011) 378:1515-25. doi: 10.1016/S0140-6736(11)60827-1

2. Belfer ML. Child and adolescent mental disorders: the magnitude of the problem across the globe. J Child Psychol Psychiatry. (2008) 49:226-36. doi: $10.1111 / j .1469-7610.2007 .01855 . x$

3. Suhrcke M, Pillas D, Selai C. Economic Aspects of Mental Health in Children and Adolescents. Social Cohesion for mental Well-Being Among Adolescents. Copenhagen: WHO Regional Office for Europe (2008).

4. Hagell A, Coleman J, Brooks F. Key Data on Adolescence 2015. London: Association for Young People's Health (2015).

5. Das JK, Salam RA, Lassi ZS, Khan MN, Mahmood W, Patel V, et al. Interventions for adolescent mental health: an overview of systematic reviews. J Adolesc Health. (2016) 59:S49-S60. doi: 10.1016/j.jadohealth.2016.06.020

6. Hagell A, Shah R. Key Data on Young People 2019. London: Association for Young People's Health (2019).

7. Murphy M, Fonagy P. Mental Health Problems in Children and Young People. Annual Report of the Chief Medical Officer (2012). p. 1-13.

8. Clarke A, Pote I, Sorgenfrei M. Adolescent Mental Health Evidence Brief 1: Prevalence of Disorders. Early Intervention Foundation. (2020).

9. NHS Digital. Mental Health of Children and Young People in England, 2020: Wave 1 Follow Up to the 2017 Survey. (2020). Available online at: https:// digital.nhs.uk/data-and-information/publications/statistical/mental-healthof-children-and-young-people-in-england/2020-wave-1-follow-up\#datasets (accessed December 05, 2020).

10. Bowes L, Joinson C, Wolke D, Lweis G. Peer victimisation among adolescence and its impact on depression in adulthood: prospective cohort study in the United Kingdom. BMJ. (2015) 350:h2469. doi: 10.1136/bmj. h2469

11. Islam MI, Khanam R, Kabir E. Bullying victimization, mental disorders, suicidality and self-harm among Australian high schoolchildren: evidence from nationwide data. Psychiatry Res. (2020) 292:113364. doi: $10.1016 /$ j.psychres.2020.113364

12. Rothon C, Head J, Klineberg E, Stansfeld S. Can social support protect bullied adolescents from adverse outcomes? A prospective study on the effects of bullying on the educational achievement and mental health of adolescents at secondary schools in East London. J Adolesc. (2011) 34:579-88. doi: 10.1016/j.adolescence.2010.02.007

\section{AUTHOR CONTRIBUTIONS}

RK conceived of the study, participated in its design and coordination and contributed toward the critical revision on all versions of the manuscript. IH drafted the manuscript and contributed to literature search, data analysis, data management, and checking of the results. AA-Z contributed to study design, literature search, data collection, and data analysis. All authors read and approved the final manuscript.

\section{ACKNOWLEDGMENTS}

We would like to thank all those who participated in the study.

\section{SUPPLEMENTARY MATERIAL}

The Supplementary Material for this article can be found online at: https://www.frontiersin.org/articles/10.3389/fpsyt. 2021.592624/full\#supplementary-material

13. Assari S, Moazen-Zadeh E, Caldwell CH, Zimmerman MA. Racial discrimination during adolescence predicts mental health deterioration in adulthood: gender differences among Blacks. Front Public Health. (2017) 5:1-10. doi: 10.3389/fpubh.2017.00104

14. Ellis BH, MacDonald HZ, Klunk-Gillis J, Lincoln A, Strunin L, Cabral HJ. Discrimination and mental health among Somali refugee adolescents: The role of acculturation and gender. Am J Orthopsychiatry. (2010) 80:564. doi: 10.1111/j.1939-0025.2010.01061.x

15. Flores E, Tschann JM, Dimas JM, Pasch LA, de Groat CL. Perceived racial/ethnic discrimination, posttraumatic stress symptoms, and health risk behaviors among Mexican American adolescents. J Couns Psychol. (2010) 57:264. doi: 10.1037/a0020026

16. Grollman EA. Multiple forms of perceived discrimination and health among adolescents and young adults. J Health Soc Behav. (2012) 53:199-214. doi: 10.1177/0022146512444289

17. Szalacha LA, Erkut S, Coll CG, Alarcon O, Fields JP, Ceder I. Discrimination and Puerto Rican children's and adolescents' mental health. Cultur Divers Ethnic Minor Psychol. (2003) 9:141-55. doi: 10.1037/1099-9809.9.2.141

18. Umaña-Taylor AJ, Updegraff KA. Latino adolescents' mental health: exploring the interrelations among discrimination, ethnic identity, cultural orientation, self-esteem, and depressive symptoms. J Adolesc. (2007) 30:54967. doi: 10.1016/j.adolescence.2006.08.002

19. Amone-P'Olak K, Burger H, Ormel J, Huisman M, Verhulst FC, Oldehinkel AJ. Socioeconomic position and mental health problems in pre-and early-adolescents. Soc Psychiatry Psychiatr Epidemiol(2009) 44:231-8. doi: 10.1007/s00127-008-0424-z

20. McLaughlin KA, Breslau J, Green JG, Lakoma MD, Sampson NA, Zaslavsky AM, et al. Childhood socio-economic status and the onset, persistence, and severity of DSM-IV mental disorders in a US national sample. Soc Sci Med. (2011) 73:1088-96. doi: 10.1016/j.socscimed.2011.06.011

21. Biddle SJ, Asare M. Physical activity and mental health in children and adolescents: a review of reviews. Brit J Sports Med. (2011) 45:886-95. doi: 10.1136/bjsports-2011-090185

22. Cao H, Qian Q, Weng T, Yuan C, Sun Y, Wang H, et al. Screen time, physical activity and mental health among urban adolescents in China. Prev Med. (2011) 53:316-20. doi: 10.1016/j.ypmed.2011.09.002

23. Kremer P, Elshaug C, Leslie E, Toumbourou JW, Patton GC, Williams J. Physical activity, leisure-time screen use and depression among children and young adolescents. Journal of Sci Med Sport. (2014) 17:183-7. doi: 10.1016/j.jsams.2013.03.012 
24. Lissak G. Adverse physiological and psychological effects of screen time on children and adolescents: literature review and case study. Environ Res. (2018) 164:149-57. doi: 10.1016/j.envres.2018.01.015

25. Maras D, Flament MF, Murray M, Buchholz A, Henderson KA, Obeid N, et al. Screen time is associated with depression and anxiety in Canadian youth. Prev Med. (2015) 73:133-8. doi: 10.1016/j.ypmed.2015.01.029

26. Twenge JM, Joiner TE, Rogers ML, Martin GN. Increases in depressive symptoms, suicide-related outcomes, and suicide rates among US adolescents after 2010 and links to increased new media screen time. Clin Psychol Sci. (2018) 6:3-17. doi: 10.1177/2167702617723376

27. Wu X, Tao S, Zhang Y, Zhang S, Tao F. Low physical activity and high screen time can increase the risks of mental health problems and poor sleep quality among Chinese college students. PLOS ONE. (2015) 10:e0119607. doi: 10.1371/journal.pone.0119607

28. Chaiton M, Cohen J, O'Loughlin J, Rehm J. Use of cigarettes to improve affect and depressive symptoms in a longitudinal study of adolescents. Addict Behav. (2010) 35:1054-60. doi: 10.1016/j.addbeh.2010.07.002

29. Chang G, Sherritt L, Knight JR. Adolescent cigarette smoking and mental health symptoms. Journal Adolesc Health. (2005) 36:517-22. doi: 10.1016/j.jadohealth.2004.05.008

30. Ferriera VR, Jardima TV, Sousaa AL, Rosa BM, Jardim PC. Smoking, alcohol consumption and mental health: data from the brazilian study of cardiovascular risks in adolescents. Addict Behav Rep. (2019) 9:100147. doi: 10.1016/j.abrep.2018.100147

31. Kuhn ES, Laird RD. Family support programs and adolescent mental health: review of evidence. Adolesc Health MedTher. (2014) 10:127-42. doi: 10.2147/AHMT.S48057

32. Traci Leven Research. Health and wellbeing survey of young people in Renfrewshire 2013(2014). Available online at: https://www.stor.scot.nhs. uk/bitstream/handle/11289/579773/Renfrewshire\%20main\%20report\%20\%20Final2.pdf? sequence=1\&isAllowed=y (accessed June 25, 2020).

33. Cronbach LJ. Coefficient alpha and the internal structure of tests. Psychometrika. (1951) 16:297 doi: 10.1007/BF02310555

34. Nunnally JC. Introduction to Psychological Measurement. New York, NY: McGraw Hill (1970).

35. NICE National Institute for Health and Care Excellence. Physical Acitivity for Children and Young People. Public Health Guideline. (2009). Available online at: https://www.nice.org.uk/guidance/ph17/resources/physical-activity-forchildren-and-young-people-pdf-1996181580229 (accessed June 25, 2020).

36. Neto F. Predictors of mental health among adolescents from immigrant families in portugal. J Family Pscyhol. (2009) 23:375-85. doi: $10.1037 / \mathrm{a} 0015831$

37. Kessler R, Chiu W, Demlar O. Prevalence, severity, and comorbidity of 12-month DSM-IV disorders in the national comorbidity survey replication. Arch Gen Psychiatry. (2005) 62:617-27. doi: 10.1001/archpsyc. 62.6 .617
38. Brooks TL, Harris SK, Thrall JS, Woods ER. Association of adolescent risk behaviors with mental health symptoms in high school students. J Adolesc Health. (2002) 31:240-6. doi: 10.1016/S1054-139X(02)00385-3

39. Moos RH, Kopell BS, Melges FT, Yalom ID, Lunde DT, Clayton RB, et al. Fluctuations in symptoms and moods during the menstrual cycle. J Psychosom Res. (1969) 13:37-44. doi: 10.1016/0022-3999(69) 90017-8

40. Fluharty M, Taylor AE, Grabski M, Munafò MR. The association of cigarette smoking with depression and anxiety: a systematic review. Nicotine Tobacco Res. (2017) 19:3-13 doi: 10.1093/ntr/ntw140

41. Hockenberry JM, Timmons EJ, Vander Weg MV. Adolescent mental health as a risk factor for adolescent smoking onset. Adolesc Health Med Ther. (2011) 2:27-35. doi: 10.2147/AHMT.S11573

42. Simantov E, Schoen C, Klein JD. Health compromising bahaviours: why do adolsecents smoke or drink? Identifying underlying risk and protective factors. Arch Pediatr Adolesc Med. (2000) 154:1025-33. doi: 10.1001/archpedi.154.10.1025

43. Duncan B, Rees DI. Effect of smoking on depressive symptomatology: a reexamination of data from the national longitudinal study of adolescent health. Am J Epidemiol. (2005) 162:461-70. doi: 10.1093/aje/kwi219

44. Patton GC, Hibbert M, Rosier MJ, Carlin JB, Caust J, Bowes G. Is smoking associated with depression and anxiety in teenagers? Am J Public Health. (1996) 86:225-30. doi: 10.2105/AJPH.86.2.225

45. Bluhm RL, Covin R, Chow M, Wrath A, Osuch EA. "I just have to stick with it and it'll work": experiences of adolescents and young adults with mental health concerns. Community Ment Health J. (2014) 50:778-86. doi: 10.1007/s10597-014-9695-x

46. O’Reilly M, Dogra N, Whiteman N, Hughes J, Eruyar S, and Paul Reilly P. Is social media bad for mental health and wellbeing? Exploring the perspectives of adolescents. Clin Child Psychol P. (2018) 23:601-13 doi: 10.1177/1359104518775154

47. Mason T, Trochez C, Thomas R, Babar M, Hesso I, Kayyali R. Knowledge and awareness of the general public and perception of pharmacists about antibiotic resistance. BMC Public Health. (2018) 18:711. doi: 10.1186/s12889-018-5614-3

Conflict of Interest: The authors declare that the research was conducted in the absence of any commercial or financial relationships that could be construed as a potential conflict of interest.

Copyright (c) 2021 Al-Zawaadi, Hesso and Kayyali. This is an open-access article distributed under the terms of the Creative Commons Attribution License (CC BY). The use, distribution or reproduction in other forums is permitted, provided the original author(s) and the copyright owner(s) are credited and that the original publication in this journal is cited, in accordance with accepted academic practice. No use, distribution or reproduction is permitted which does not comply with these terms. 